\title{
Feeding practices and nutritional status of Mexican children affiliated to the Medical Insurance for a New Generation
}

\author{
Samuel Flores-Huerta, MD,(I) Miguel Klünder-Klünder, MSc,(I) Onofre Muñoz-Hernández, MD, MSc.(I)
}

\author{
Flores-Huerta S, Klünder-Klünder M, \\ Muñoz-Hernández $O$. \\ Feeding practices and nutritional status \\ of Mexican children affiliated to the Medical Insurance \\ for a New Generation. \\ Salud Publica Mex 20I2;54 suppl I:S20-S27.
}

\begin{abstract}
Objective. To identify feeding practices and nutritional status in children affiliated to the Medical Insurance for a New Generation (SMNG). Materials and methods. An in-home survey addressed to mothers which included anthropometric measures of children; performed in March and April 2009 in Mexican States. Results. The prevalence of any form of breastfeeding was (months) 6-II: 67.9\%; 12-17: 43.6\%; 1823: $26.4 \%$; $>23$ : $16.7 \%$; with higher figures in rural children. BF duration was eight months. Continued breastfeeding at I year of age was $43 \%$. At I year of age, almost all children consumed fruits, vegetables, cereals and legumes; however, 13.5\%-20.3\% did not consume foods of animal origin, but $\sim 84 \%$ and $\sim 60 \%$ consumed fried and sweet foods and soft drinks. Nutrisano (a food supplement) was consumed by just $2 / 3$ of the Oportunidades Children. Stunting and overweight were the predominant alterations of nutritional status. Conclusion. Improving the nutritional status of children affiliated to the SMNG requires promotion of appropriate healthy dietary practices and the surveillance of infant growth.
\end{abstract}

Key words: breastfeeding; feeding practices; infant nutrition; nutritional status; overweight; Mexico
Flores-Huerta S, Klünder-Klünder M, Muñoz-Hernández $O$.

Prácticas de alimentación y estado de nutrición de los niños mexicanos afiliados al Seguro Médico para una Nueva Generación.

Salud Publica Mex 20I2;54 supl I:S20-S27.

\section{Resumen}

Objetivo. Conocer las prácticas de alimentación y estado nutricio de niños protegidos por el Seguro Médico para una Nueva Generación (SMNG). Material y métodos. Encuesta en hogares realizada en marzo y abril de 2009 en los diferentes estados de México. Resultados. La prevalencia de lactancia materna fue (meses) 6-II: 67,9\%; 12-17: 43,6\%; 18-23: 26.4\%;> 23: 16,7\%, la duración fue ocho meses. La lactancia materna continuada a I año fue $43 \%$. Al año, casi todos los niños consumen frutas y verduras, cereales y leguminosas, pero los de origen animal no están consolidados. Una gran proporción de niños de un año consume alimentos potencialmente obesogénicos; 2/3 de los niños de Oportunidades consumen Nutrisano. El retraso del crecimiento y el sobrepeso fueron las alteraciones predominantes del estado nutricional. Conclusión. Mejorar el estado nutricional de los niños afiliados al SMNG requiere la vigilancia de indicadores de prácticas de alimentación y de su crecimiento.

Palabras clave: lactancia materna; dieta complementaria; lactantes; estado de nutrición; sobrepeso; México

(I) Hospital Infantil de México Federico Gómez. México DF, México.

Received on: February 10, 20II - Accepted on: July I, 20II

Corresponding author: Dr. Samuel Flores-Huerta. Hospital Infantil de México Federico Gómez. Dr. Márquez 162, Col. Doctores.

06720 Delegación Cuauhtémoc. México, DF, México.

E-mail: floreshuertamd@gmail.com 
$\mathrm{D}$ uring the first years of life, feeding practices directly influence physical growth in children, which is a proxy of children's health status. ${ }^{1-4}$ Knowledge of feeding practices is, therefore, essential for measuring the impact of environmental factors related to energy intake on growth. On the other hand, measuring weight and length, starting from birth and throughout the first two years of life, provides an opportunity for ensuring that children's growth has the appropriate characteristics.

In December 2006, the government of Mexico launched the Medical Insurance for a New Generation (Seguro Médico para una Nueva Generación, SMNG) to guarantee healthcare services for children who at birth do not have any form of health insurance. ${ }^{5,6}$ In 2009, three years after SMNG was implemented in medical units, it was thought imperative to assess the health status of these children. For this purpose, the first National Survey for SMNG was designed whose details may be consulted in the methodology section of this supplement. Because feeding practices are determinants of health at all ages, but have greater relevance in young children, in this report, we will describe these practices in children affiliated to the SMNG, with emphasis on breastfeeding (BF) and complementary feeding $(\mathrm{CF})$ with the purpose of identifying opportunities for improvement. In addition we will also describe the children's nutritional status with particular attention to the fraction manifesting growth alterations associated with either deficit or excess of energy.

\section{Materials and methods}

The survey protocol was approved by the Research and Ethic Committees of the Hospital Infantil de Mexico Federico Gómez (HIMFG). The survey included demographic, socioeconomic, health (feeding practices and nutritional status), use of healthcare services and infant mortality information. Personnel of both HIMFG, and the National Institute for Statistics and Geography (Instituto Nacional de Estadística y Geografía, INEGI), provided appropriate training in interviewing, information gathering and cartographic techniques to supervisors from each of the participating states of Mexico. Likewise, supervisors were standardized in measuring the weight and length procedures of children under two years of age; afterwards, the course was reproduced by supervisors in each state in order to train the pollster's team, with the only exception that they were no longer given standardized methods for anthropometric measuring. However, during field work, a couple of independent measurements of length were taken by pollsters and supervisors, giving an intra- and inter-observer variability close to the unit. ${ }^{78}$ After training, a pilot study was carried out in each state to provide feedback on the logistics of the survey processes. Then, after an exhaustive localization of the children's homes, in March and April of 2009, pollsters applied the survey, under strict oversight of supervisors and with previous written informed consent given by the parents. Participants were children of $\geq 6$ months of age on the date of interview, and had a document accrediting them as SMNG beneficiaries. The sample for collecting information about health items, and subsample for assess nutritional status, were estimated in 12240 and 6240 children respectively. Mothers were asked about breast and CF practices; when they were absent, the pollster arranged an appointment, and carried out a total of 8328 full interviews and measuring 4342 children. The following indicators were assessed following the 2008 and 2010 WHO indicators: ${ }^{9} 1$ ) Children ever breastfed (regardless of what other fluids or foods the infant might receive). 2) Continued breastfeeding at 1 year of age. 3) Continued breastfeeding at 2 years of age. 4) Duration in months of breastfeeding. The questions were not designed to determine whether breastfeeding was exclusive, full or partial. For $\mathrm{CF}$, the indicators assessed were: 5) Introduction of solid, semisolid or soft foods (asking about the main groups of foods including the staple foods). 6) Minimum dietary diversity. Other feeding indicators were assessed, such as intake of sweet beverages and processed foods with high energy density. Indicators for nutritional status were: 7) Weight/Age (W/A). 8) Length/Age (L/A) and 9) Body Mass Index (BMI). Weight was obtained using an electronic scale with $10 \mathrm{~g}$ precision and length was measured twice using a portable infantometer. $Z$ scores were calculated with the software WHO ANTHRO 2006. ${ }^{10}$ The nutritional status was obtained using the criterion proposed by the World Health Organization in 2006: underweight if the W / A was <-2 Z scores; stunting if the L/A was $<-2 \mathrm{Z}$ scores; wasting if the $\mathrm{W} / \mathrm{L}$ was $<-2 \mathrm{Z}$ scores and overweight if the BMI was $>2 \mathrm{Z}$ scores. Children who presented none of the described diagnoses were considered with normal nutritional status. Data were analyzed with the software STATASE 11.0. Proportions and measurements of central and dispersion trends were calculated with expansion factors corresponding to the respective sample or subsample. Comparisons of proportions were made with the $\chi^{2}$ test and comparisons of means with Student's $t$ test.

\section{Results}

\section{Breastfeeding}

The values of BF prevalence correspond to children between six months and two years of age, who at date 
of interview still received breastfeeding. Table I shows that, from 6 - > 23 months of age, BF prevalence decreases from $67.9 \%$ to $16.7 \%$; children living in rural areas have higher values than urban children. The same table shows the duration of breastfeeding, obtained from children who at date of interview were no longer breastfed. Contrary to what was observed in the case of BF prevalence, the median of duration in months increased from 4 to
10 months, with the median of duration before 2 years being of 8 months, with two months more in children living in rural areas.

\section{Complementary feeding}

Table II shows the patterns of consumption of CF by children at one year of age or more. The Table shows

Table I

Prevalence and duration of breastfeeding, by months of age and Place of residence. Mexico 2009

\begin{tabular}{|c|c|c|c|c|c|c|c|c|c|c|c|c|c|}
\hline \multirow{3}{*}{ Age (Months) } & \multicolumn{6}{|c|}{ Prevalence (\%)* } & \multirow{3}{*}{$\begin{array}{c}\text { Prevalence } \\
\%\end{array}$} & \multicolumn{6}{|c|}{ Duration (months) $)^{\ddagger}$} \\
\hline & \multicolumn{2}{|c|}{$\begin{array}{l}\text { Nationwide } \\
N=1370155\end{array}$} & \multicolumn{2}{|c|}{$\begin{array}{c}\text { Rural } \\
N=392854\end{array}$} & \multicolumn{2}{|c|}{$\begin{array}{c}\text { Urban } \\
N=977301\end{array}$} & & \multicolumn{2}{|c|}{$\begin{array}{c}\text { Nationwide } \\
N=1370 / 55\end{array}$} & \multicolumn{2}{|c|}{$\begin{array}{c}\text { Rural } \\
N=392854\end{array}$} & \multicolumn{2}{|c|}{$\begin{array}{c}\text { Urban } \\
N=977301\end{array}$} \\
\hline & $n$ & $\%$ & $n$ & $\%$ & $n$ & $\%$ & & median & $\min -\max$ & median & $\min -\max$ & median & $\min -\max$ \\
\hline $6-11$ & 1993 & 67.9 & 1052 & 74.6 & 941 & 60.4 & 32.1 & 4 & $0-11$ & 4 & $0-11$ & 4 & $0-11$ \\
\hline $12-17$ & 2383 & 43.6 & 1279 & 49.7 & 1107 & 36.5 & 56.4 & 7 & $0-17$ & 8 & $0-17$ & 6 & $0-17$ \\
\hline $18-23$ & 2423 & 26.4 & 1303 & 30.5 & 1120 & 21.6 & 73.6 & 8 & $0-23$ & 10 & $0-23$ & 7 & $0-23$ \\
\hline$>23$ & 1526 & 16.7 & 851 & 19.4 & 675 & 13.3 & 83.3 & 10 & $0-26$ & 12 & $0-24$ & 9 & $0-26$ \\
\hline Total & 8328 & 39.5 & 4485 & 44.2 & 3843 & 33.9 & 60.5 & 8 & $0-26$ & 8 & $0-24$ & 6 & $0-26$ \\
\hline
\end{tabular}

Table II

Age at Which Children over I Year of Age consume Regularly complementary foods. Mexico 2009

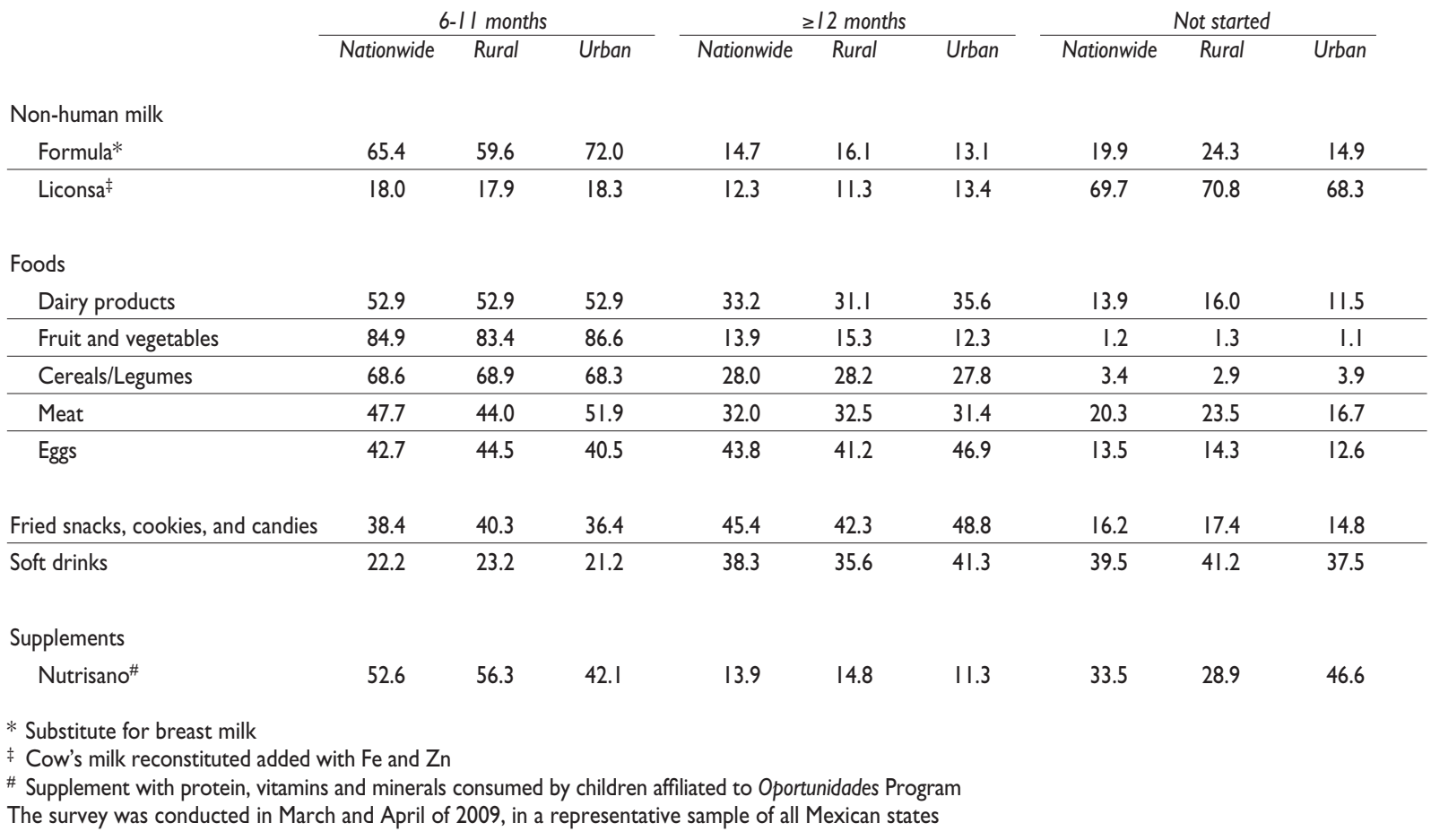


that between 6 to 11 months of age, $65.4 \%$ of children consumed formula, $59.6 \%$ in rural areas and $72.0 \%$ in urban areas. Liconsa cow's milk was ingested regularly by $18 \%$ of the infants, with equal figures for rural and urban children. After one year of age, almost $70 \%$ of infants did not ingest Liconsa cow's milk. As regards complementary foods, the assessment considered the consumption of solids or liquids, by healthy or with risk for health children. The cluster of healthy food groups included dairy products, fruits and vegetables, cereals and legumes, and meat and eggs. Between 6 to 11 months of age, $\sim 85 \%$ of children regularly ingested fruits and vegetables and $\sim 69 \%$ ingested cereals and legumes. On the other hand, less than half of children in this age group ingested meat and eggs. After one year of age, almost all children consumed fruits and vegetables, as well as cereals and legumes. However, 13.9\%, 20.3\% and $13.5 \%$ of children did not ingest dairy products, meat and eggs, respectively. This lack of intake of animal products was higher among children living in rural areas. However, consumption of fried snacks, cookies and candies was present in one third or more of children aged from 6 to11 months, this consumption increased in the second year of life, especially among urban children. Likewise, consumption of soft drinks was around 22\% between 6 to11 months of age, and the consumption of these beverages increased to $\sim 60 \%$ in the second year of life. As for Nutrisano, the nutritional supplement addressed for Oportunidades Program children, it was consumed by $\sim 53 \%$ of children aged between 6 to11 months; however, although after the first year of life consumption increased, one third of the Oportunidades children did not receive this supplement.

\section{Indicators of infant feeding practices}

Figure 1 shows some BF and CF indicators. Before two years of age, $91 \%$ of infants were ever breastfed, a figure that was higher in rural areas. However, at 1 year of age, just $43 \%$ continued breastfeeding, with higher rates in rural (55\%) than in urban areas (39\%). At two years of age, these values had decreased by half.

The same figure shows that a) $94 \%$ of children between 6-8 months of age in both rural and urban areas were receiving solid or semisolid foods other than human milk or a substitute; and b) between 6 to 23 months of age, $77 \%$ of children had a minimum dietary diversity, which means that they received foods from at least four groups.

\section{Nutritional status}

Children's nutritional status is shown in Table III, where we can see that diagnosis showed variations by age, gender, and place of residence; $75.5 \%$ of children covered by the SMNG were found to have a normal nutritional status with a lower proportion of males (72.8\%) than females $(78.3 \%)$. We can also observe that children living

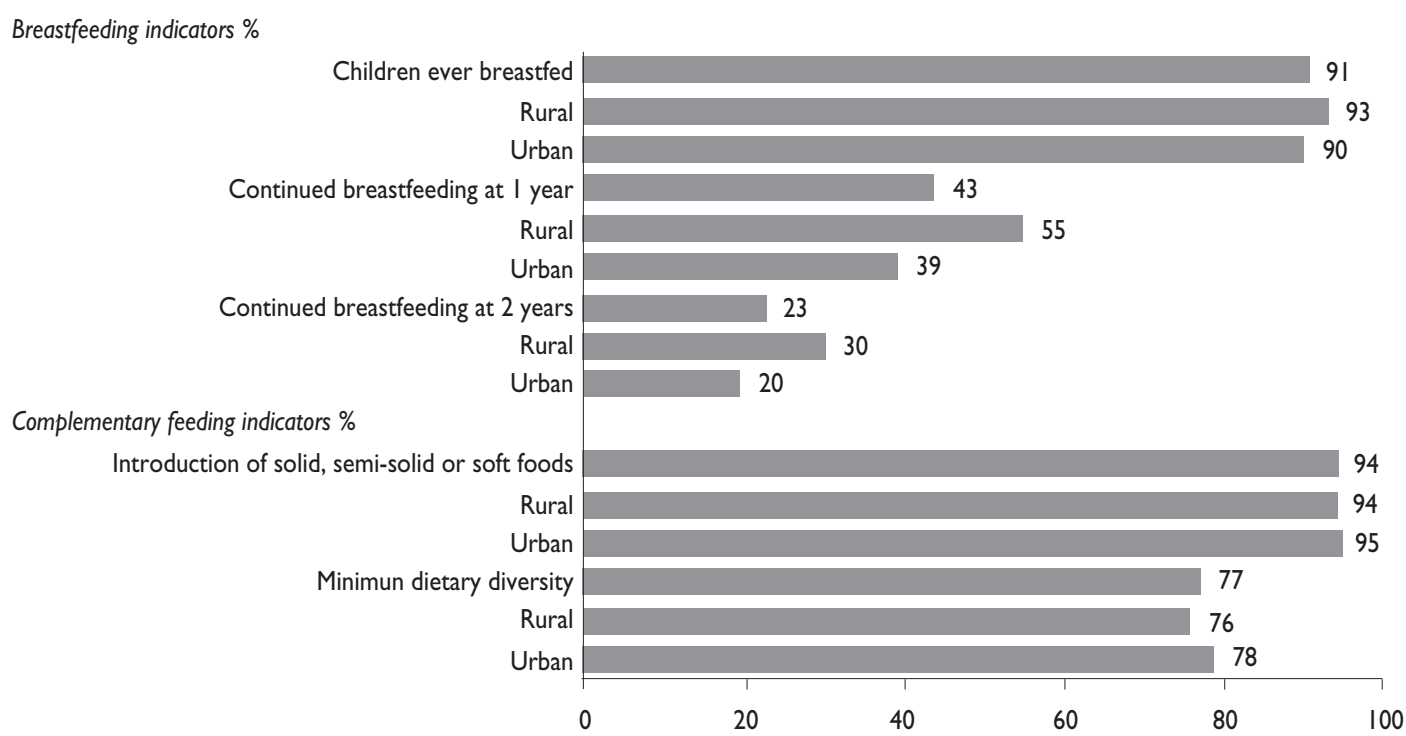

FIGURE I. INDICATORS OF BREASTFEEDING AND COMPLEMENTARY FEEDING IN CHILDREN COVERED BY THE SMNG, BY RESIDENCE area. The survey was conducted in March and April of 2009, in a representative sample of all Mexican states 
Table III

Nutritional status of Children under 2 years covered by the SMNG. Mexico 2009

\begin{tabular}{|c|c|c|c|c|c|c|c|c|c|c|c|c|}
\hline \multirow[b]{2}{*}{ Age (months) } & \multicolumn{4}{|c|}{ Nationwide } & \multicolumn{4}{|c|}{ Rural } & \multicolumn{4}{|c|}{ Urban } \\
\hline & 6 to 11 & 12 to 23 & $>23$ & Total & 6 to 11 & 12 to 23 & $>23$ & Total & 6 to 11 & 12 to 23 & $>23$ & Total \\
\hline N & 394470 & 855351 & 264137 & 1513958 & 110511 & 235405 & 78474 & 424390 & 283959 & 619946 & 185663 & 1089568 \\
\hline
\end{tabular}

Normal

\begin{tabular}{|c|c|c|c|c|c|c|c|c|c|c|c|c|}
\hline Total & 78.3 & 73.6 & 77.4 & 75.5 & 76.5 & 73.4 & 69.6 & 73.5 & 79.0 & 73.7 & $80.6^{8}$ & $76.3^{8}$ \\
\hline Female & 82.1 & 76.6 & 78.4 & 78.3 & 82.2 & 73.9 & 73.2 & 75.8 & 82.1 & 77.6 & 80.5 & 79.3 \\
\hline Male & $74.8^{\infty}$ & $70.8^{\infty}$ & 76.4 & $72.8^{\circ}$ & $71.3^{\infty}$ & 72.8 & 66.4 & 71.2 & $76.1^{\infty}$ & $70.0 \mathrm{~d}$ & 80.7 & $73.4^{\circ}$ \\
\hline
\end{tabular}

Underweight*

\begin{tabular}{|c|c|c|c|c|c|c|c|c|c|c|c|c|}
\hline Total & 5.6 & 4.8 & 4.8 & 5.0 & 6.4 & 4.9 & 7.3 & 5.7 & 5.3 & 4.8 & $3.7^{\&}$ & 4.8 \\
\hline Female & 4.4 & 3.7 & 5.0 & 4.1 & 3.0 & 4.2 & 5.2 & 4.0 & 5.0 & 3.4 & 4.9 & 4.1 \\
\hline Male & 6.8 & $6.0^{\infty}$ & 4.6 & $5.9^{\circ}$ & $9.5^{\infty}$ & 5.7 & 9.1 & $7.4^{\infty}$ & 5.7 & $6.1^{\infty}$ & 2.6 & $5.4^{\infty}$ \\
\hline
\end{tabular}

Stunting ${ }^{\ddagger}$

\begin{tabular}{lcccccccccccc} 
Total & 10.0 & 15.4 & 13.1 & 13.6 & 12.0 & 18.0 & 21.9 & 17.2 & 9.2 & 14.4 & $9.3^{b}$ & $12.1^{*}$ \\
\hline Female & 7.0 & 11.7 & 12.3 & 10.6 & 7.6 & 15.7 & 19.0 & 14.3 & 6.8 & 10.1 & 9.6 & 9.1 \\
\hline Male & $12.6^{\circ}$ & $19.0^{\circ}$ & 13.8 & $16.4^{\circ}$ & $15.9^{\infty}$ & 20.3 & 24.6 & $19.9^{\infty}$ & $11.4^{\infty}$ & $18.5^{\circ}$ & 9.1 & $15.0^{\circ}$
\end{tabular}

Wasting $\S$

\begin{tabular}{|c|c|c|c|c|c|c|c|c|c|c|c|c|}
\hline Total & 4.9 & 3.4 & 3.2 & 3.8 & 4.8 & 2.8 & 2.1 & 3.2 & 4.9 & $3.5^{\&}$ & 3.4 & 3.9 \\
\hline Female & 3.4 & 2.5 & 2.5 & 2.7 & 3.9 & 2.6 & 0.0 & 2.5 & 3.3 & 2.5 & 3.0 & 2.8 \\
\hline Male & 6.3 & 4.2 & 3.8 & $4.8^{\infty}$ & 5.6 & 3.0 & $3.0^{\infty}$ & 3.9 & 6.5 & 4.4 & 3.8 & 4.9 \\
\hline
\end{tabular}

Overweight ${ }^{\#}$

\begin{tabular}{|c|c|c|c|c|c|c|c|c|c|c|c|c|}
\hline Total & 4.5 & 7.2 & 6.3 & 6.3 & 3.5 & 6.1 & 6.1 & 5.4 & 4.9 & 7.7 & 6.4 & 6.7 \\
\hline Female & 5.6 & 7.2 & 6.0 & 6.6 & 3.2 & 7.0 & 7.4 & 6.1 & 6.5 & 7.3 & 5.4 & 6.8 \\
\hline Male & 3.5 & 7.2 & 6.7 & 6.1 & 3.7 & 5.2 & 4.9 & 4.7 & 3.5 & 8.0 & 7.4 & 6.6 \\
\hline
\end{tabular}

SMNG: New Generation Medical Insurance

The values are percentages. Based on the 2006 WHO growth standard, the following indicators were obtained:

$*$ Weight/Age $<-2$ Z

$\ddagger$ Lenght/Age $<-2 Z$

$\S$ Weight/Length $<-2 Z$

\# Body mass index $>2 Z$

$\& p<0.05$ rural vs. urban

$\neq p<0.00$ I rural vs. urban

${ }^{\infty} \mathrm{p}<0.05$ female vs. male

${ }^{\circ} \mathrm{p}<0.00$ I female vs. male

The survey was conducted in March and April of 2009, in a representative sample of all Mexican states

in rural areas had a lower incidence of normality $(73.5 \%)$ than children living in urban areas $(76.3 \%)$.

With regard to child malnutrition, the survey found that $5 \%$ of children presented underweight; boys having rates higher than girls, $5.9 \%$ vs. $4.1 \%,(p<0.001)$ in both rural and urban areas.

Concerning stunting, which is interpreted as the cumulative negative impact on linear growth caused by poor feeding practices in quantity and / or quality, or an excess expenditure of energy caused by infections; boys were more affected than girls, especially if they were liv- ing in rural areas. Of $13.6 \%$ of all diagnosed with stunting, $10.6 \%$ were girls and $16.4 \%$ boys $(p<0.001)$. In rural areas, the total prevalence of stunting was $14.3 \%$ among girls and $19.9 \%$ among boys; in urban areas, the figures were $9.1 \%$ and $15 \%$ for girls and boys, respectively. It is important to highlight that the prevalence of stunting increased with age, reaching at two years of age $19 \%$ of girls and $24.6 \%$ of boys in rural areas. Figure 2 shows that stunting increased with age; at two years of age, retarded growth reached an $\sim-1 \mathrm{Z}$ score in rural areas, whereas in urban areas the $\mathrm{Z}$ score was $\sim-0.5$. 


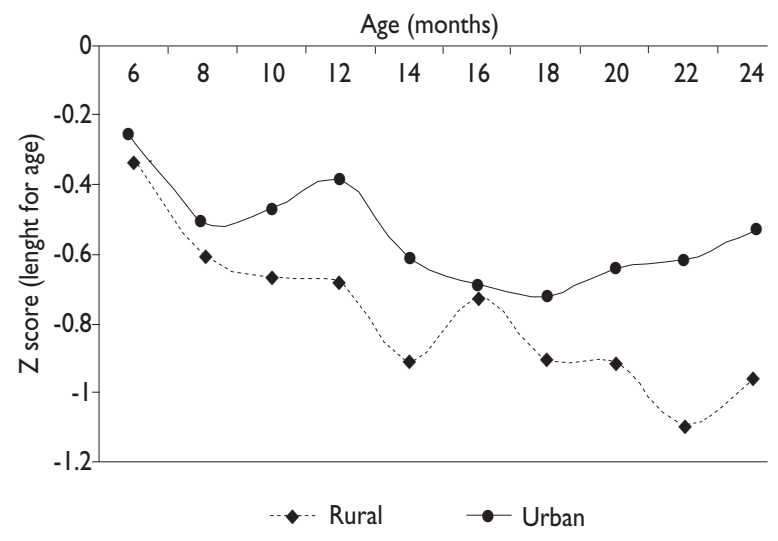

SMNG: New Generation Medical Insurance

FIGURE 2. Z SCORE OF LENGHT FOR AGE OF CHILDREN COVERED BY THE SMNG, BY PLACE OF RESIDENCE, COMPARED WITH THE 2006 WHO GROWTH STANDARD. THE SURVEY WAS CONDUCTEd IN MARCH AND APRIL Of 2009, in A Representative sample of all Mexican states

In terms of wasting, which is an indicator of acute malnutrition, the total prevalence was 3.8\%; $2.7 \%$ vs. $4.8 \%$ for girls and boys, respectively $(p<0.05)$; likewise, according to age, in the first year of life prevalence was higher than in the second year $(4.9 \%$ vs. $3.2 \%$, respectively) but there were no differences by residence area. Prevalence of overweight was observed in 6.3\% of children, with girls presenting a higher proportion (6.6\%) than boys (6.1\%). In rural areas, girls had a higher overweight prevalence than boys (6.1\% vs. $4.7 \%$, respectively); whereas in urban areas prevalence was $6.8 \%$ vs. $6.6 \%$ for girls and boys, respectively. These values are not statistically different.

\section{Discussion}

Improving children's feeding practices between 0 to 23 months of age is critical for improving their nutrition, health and development. ${ }^{11,12}$ With this purpose in mind, information on both $\mathrm{BF}$ and $\mathrm{CF}$ practices was collected in children covered by SMNG for obtaining basal information, useful to compare future evaluations. As far as the assessment of $\mathrm{BF}$ is concerned, this survey indicates that $9 \%$ of children did not initiate BF $(91 \%$ of children were ever breastfed). For a vulnerable population, it is to be expected that BF initiation will be higher than this figure, suggesting that medical units where babies of this study were born had not implemented the guidelines of the Baby Friendly Hospitals (BFHI) ${ }_{i}^{13}$ however, when these guidelines are followed, the percentage of newborns who do not initiate $\mathrm{BF}$ is $<5 \%$ and $<2 \%$ for cesarean section and vaginal births, respectively. ${ }^{4}$
In terms of the prevalence of any form of $\mathrm{BF}$, the values of this survey are higher than those reported by two other surveys [Mexico's National Nutritional Survey $1999^{14}$ (ENN 99) and Dietary Practices, Nutritional Status, and Healthcare in Children under two Years of age in Mexico ${ }^{4}$ (IMSS 04)]. The prevalence of BF reported in ENN 99 between 6 to 11 months was $51.5 \%$; whereas for urban areas in the IMSS 04 survey prevalence was $43.3 \%$, and for SMNG children of this study prevalence was $67.9 \%$. Although the figures of this study are higher than those of others, unfortunately, we do not have enough information to explain this finding.

With regard to BF duration, comparing the values of this survey with data of ENN 99, duration had diminished in urban areas from 7 to 6 months, and in rural areas from 14 to 8 months.

In relation to the consumption of complementary foods, it is interesting to note that of the five food groups included in this survey, fruits and vegetables are the most consumed, followed by cereals and legumes; foods which after the first year of age are part of the children's diet pattern. However, foods from animal sources, which are the vehicle to deliver nutrients for growth, such as high nutritional value proteins, iron and other micronutrients, ${ }^{15}$ were less frequently consumed; more than half of the infants beyond the first year not ingesting them regularly.

Regarding consumption by children of foods with high energy density, and considered as foods with risk for health, it is worrying that fried and sweet foods were consumed by around $84 \%$ of children (only $16.2 \%$ of children after one year of age did not consume these foods); in addition, almost $60 \%$ of children under one year of age regularly consumed soft drinks $(39.5 \%$ of them did not consume these beverages). Second, within the fraction of children covered by Oportunidades Program, 1/3 did not consume Nutrisano, which is a nutritional supplement rich in proteins, vitamins and minerals needed for an adequate growth attainment in children less than five years of age.

As regards the nutritional status of children attended by SMNG, the anthropometric indicators show figures within the range of or similar to those reported by related surveys. ${ }^{16}$ Despite this it is pertinent to remark that some differences can be explained by methodological rather than biological factors. Although in both studies the cutoff point was $-2 \mathrm{Z}$ scores, this study used mainly the BMI, whereas the National Health and Nutritional Survey $2006{ }^{16}$ (ENSANUT 06) used W/H or W/A. Also, this study used as referent the WHO 2006 growth standard, whereas the ENSANUT 06 used NCHS and CDC 2000 or those proposed by Cole. ${ }^{17}$ 
Among children of this study, underweight was reported at 5\%, with a slightly higher level in rural areas. This figure is within the range reported in the ENSANUT $06{ }^{16}$

Stunting was observed in $13.6 \%$ of children under two years of age, this value lies in the middle of that of 9.5\% to $18.3 \%$ reported by ENSANUT 06. Although the design of this evaluation does not allow us to establish causality in terms of intake or expenditure of energy, two facts could be related to explain the increasing trend of this problem in both rural and urban children: first, many children less than one year of age did not consume regularly foods of animal origin and the Nutrisano supplement was consumed just by 1 out of 3 children in the Oportunidades program. However, we believe that this problem could be reverted if the procedures to improve children's feeding practices are reinforced; if the mothers are informed about the benefits of $\mathrm{Nu}$ trisano, and if children's physical growth is monitored in primary health units.

As regards wasting, this study showed a prevalence of $3.8 \%$ in children less than two years of age, the prevalence being higher in boys than in girls and higher also in children in the first than in the second year of life. This figure is almost twice that of $2.1 \%$ and 2.0 reported by ENN 99 and ENSANUT 06, respectively; however, before admitting that there is an emergency state due to acute malnutrition, it is pertinent to take in account that this report compares the values obtained with the OMS 06 referent, which gives a higher prevalence than NCHS/WHO. ${ }^{18,} 19$ Second, the values of ENN 99 and ENSANUT 06 are for children under five years of age, which are less than values for children under two. Probably, the better referent will be the IMSS 04 study, owing to the fact that it was performed in children of the same age but with higher life standards, among which the prevalence of wasting was 3.5\% for urban children and $3.9 \%$ for rural children. ${ }^{4}$ Wasting prevalence in these children is practically the same as in children less than 2 years old, indicating that the problem remains with the same figures but require continuous surveillance and support by means of adequate feeding practices.

In the case of overweight, prevalence was $6.3 \%$, a figure slightly higher than that reported by ENSANUT 06; likewise, the stunting and elevated levels of consumption of high-energy-density foods and beverages observed in this study could be a risk factor for the early appearance of overweight and may contribute to the increasing trend of overweight in the following years. ${ }^{20}$

Based on the present assessment of feeding practices in children covered by the SMNG, we believe that there are several opportunities for improving these practices and the nutritional status of these children. To start with, it will be useful to implement a system for monitoring all $\mathrm{BF}$ and $\mathrm{CF}$ indicators; the lack of these indicators does not permit Mexico to be included in the international comparisons study on BF elaborated by the World Health Organization. ${ }^{9}$

For improving BF indicators, such as exclusivity and duration, as mentioned above, it will be useful to assimilate the lessons learned and given by BFHI as well as the World Alliance for Breastfeeding Action acting as a global network, ${ }^{21}$ implementing, especially in primary health units and hospitals where the children are born, actions to promote and preserve BF. However, like children themselves, $\mathrm{BF}$ is highly vulnerable and, therefore, this feeding mode should be protected involving all health workers in this mission and inviting the industry to produce formulas respecting the International Code of Marketing of Breast-milk Substitutes. ${ }^{22}$ Protecting the $\mathrm{BF}$ is not only valuable on nutritional grounds but also for its contribution to the general well-being and development of infants.

Finally, remedial action is required to address the lack of suitable foods to complement breastfeeding; increasing of intake foods such as those of animal origin must be encouraged, and the intake of foods such as snacks and sweetened beverages must decline. All this, added to a strategy that includes monitoring of children's growth with both continuous system and sporadic surveys, will help us to learn more about the epidemiological behavior of child malnutrition in children covered by SMNG.

Thus the knowledge gained could be helpful in implementing programs to tackle these problems bearing in mind that many of the leading causes of death in adults, have strong roots in feeding practices acquired early in life and in growth deviations observed during childhood.

Declaration of conflict of interests. The authors declare that they have no conflict of interests.

\section{References}

I. León-Cava N, Lutter C, Ross J, Martin L. Quantifying the benefits of breastfeeding: A summary of the evidence. Washington, DC: PAHO, 2002. 2. World Health Organization. Guiding principles for feeding non-breastfed children 6-24 months of age. Geneva: World Health Organization, 2005.

3. World Health Organization/UNICEF. Protecting, promoting and supporting breastfeeding: the special role of maternity services. Geneva:WHO, 1989.

4. Flores-Huerta S, Martínez-Salgado H. Prácticas de alimentación, estado de nutrición y cuidados a la salud en niños menores de 2 años en México. atendidos por el Instituto Mexicano del Seguro Social. I ed. México, DF: IMSS, 2004

5. Secretaría de Gobernación, Diario Oficial de la Federación. Acuerdo por el que se emiten las Reglas de Operación del Programa Seguro 
Médico para una Nueva Generación, para el Ejercicio Fiscal 20I0. México, DF: Secretaría de Gobernación, 2009.

6. Seguro Popular. Acuerdo por el que se emiten las Reglas de Operación del Programa Seguro Médico para una Nueva Generación, para el Ejercicio Fiscal 2009. Decimotercera Sección. México: Secretaría de Salud, 2008.

7. Habicht JP. Estandarización de métodos epidemiológicos cuantitativos sobre el terreno. Bull Pan Am Health Organ 1974; 76:375-384. 8. Muñoz-Hernández O, Cortés-Gallo G, Pérez-Cuevas R, GarduñoEspinosa J, Durán-Arenas L, Flores-Huerta S, et al. Evaluación del Seguro Médico para una Nueva generación. México: Hospital Infantil de México Federico Gómez, 2009.

9. World Health Organization. Indicators for assessing infant and young child feeding practices. Part 3: country profiles. Geneva: WHO Press, 2010 10. World Health Organization. WHO Child Growth Standards. Length/ height-for-age, weight-for-age, weight-for-length, weight-for-height and body mass index-for-age. Methods and development. Geneva: WHO, Department of nutrition for health and development, 2006.

II. American Academy of Pediatrics. Policy Statement. Breastfeeding and the use of human milk. Pediatrics 2005; II 5 496-506.

12. Lung'aho MS, Huffman SL, Labbok MH, Sommerfelt E, Baker J. Tool kit for monitoring and evaluating breastfeeding practices and programs. San Diego, CA: USAID 1996

13. Perez-Escamilla R. Evidence based breast-feeding promotion: The babyfriendly hospital initiative. J Nutr 2007; 137:484-487.

14. Rivera-Dommarco J, Shamah-Levy T, Villalpando-Hernández S, González-de Cossío T, Hernández-Prado B, Sepúlveda J. Encuesta Nacional de Nutrición 1999. Estado nutricio de niños y mujeres en México Cuernavaca Morelos México: Instituto Nacional de Salud Pública, 200I.
15. Flores-Huerta S, Martínez-Andrade G, Toussaint G, Adell-Gras A, Copto-García A. Alimentación complementaria en los niños mayores de seis meses de edad. Bases técnicas. Bol Med Hosp Infant Mex 2006;63:129-144.

16. Olaiz-Fernández G, Rivera-Dommarco J, Shamah-Levy T, Rojas R, Villalpando-Hernández S, Hernández-Avila M, et al. Encuesta Nacional de Salud y Nutrición 2006. Cuernavaca, México: Instituto Nacional de Salud Pública, 2006.

17. Cole TJ, Bellizzi MC, Flegal KM, Dietz WH. Establishing a standard definition for child overweight and obesity worldwide: International survey. BMJ 2000;320: I240-I243.

I8. González-de Cossío T, Rivera JA, González-Castell D, Unar-Munguía M, Monterrubio EA. Child malnutrition in Mexico in the last two decades: prevalence using the new WHO 2006 growth standards. Salud Publica Mex 2009;5I:S494-S506.

19. Kerac M, Blencowe H, Grijalva-Eternod C, McGrath M, Shoham J, Cole TJ, et al. Prevalence of wasting among under 6-month-old infants in developing countries and implications of new case definitions using WHO growth standards: a secondary data analysis. Arch Dis Child 20I I;96(I I): $1008-1013$.

20. Fernald L, Neufeld L. Overweight with concurrent stunting in very young children from rural Mexico: prevalence and associated factors. Eur J Clin Nutr 2007;61:623-632.

21. World Alliance for Breastfeeding Action. Protecting, promoting and supporting continued breastfeeding from 6-24 + Months: Issues, politics, policies and action. Global Breastfeeding Partners Meeting VII. Penang, Malaysia: WABA, 2009.

22. World Health Organization. International code of marketing of breast-milk substitutes. Geneva: WHO, I98I. 